\title{
Cuba and China, a Paradigmatic Partnership in a Changing World Context
}

\author{
Carlos Miguel Pereira Hernández
}

\section{A Relationship with 60 Years of History}

On September, 28, 2020, Cuba and China celebrated the 60th anniversary of the establishment of diplomatic relations, an event that transcends the ties between Cuba and China, since it also represents the beginning of relations between China and the Latin American and Caribbean region. This year also marks a landmark event, the 100th Anniversary of the Communist Party of China, a testament to its will and determination to lead China forward.

On September 2, 1960, an unprecedented event occurred in international relations: José Martí Revolution Square, the Cuban equivalent of Tiananmen Square, thousands of people gathered listening to the leader of the revolution, who suddenly announced the breakdown of relations with the regime in Taiwan (Cuba had a small Taiwanese embassy), and recognition of the People's Republic of China.

The entire population gathered and approved it, inserting it into a document called "First Declaration of Havana," and from there, links between the two revolutions were established. In November 1960, an official government economic delegation led by revolutionary leader Ernesto "Che" Guevara visited China, where he was received by Chairman Mao Zedong and other Chinese leaders. The governments of the two countries signed their first economic and technological cooperation agreement. In December, Guo Moruo, Vice President of the Standing Committee of the National People's Assembly (APN), led a delegation of friendship to participate in the celebration activities on the second anniversary of the victory of the Cuban revolution. In September 1961, then-Cuban President, Osvaldo Dorticós, undertook a visit to China. Ernesto "Che" Guevara visited China again in 1965 where he was received by the country's top authorities and visited several Chinese provinces.

It must be said that the meeting between the Cuban and Chinese revolutions was a totally natural and logical process: They were two popular, radical revolutions, led

C. M. P. Hernández (凶)

Embassy of the Republic of Cuba to the People's Republic of China, Beijing, China 
in China by its Communist Party, and in Cuba by the "July 26 Movement," both with the support of different social strata of the population. The two victories were twinned in time, and in history, to those two radical processes, which at their peak had two leaders of the stature of Fidel Castro and Mao Zedong.

Fidel Castro's first visit to China in 1995 was historic. He visited several places that allowed him to see China's industrial, urban and rural development. He held exchanges with then-President Jiang Zemin and Li Peng, then-Prime Minister. Fidel was very impressed with the development he had seen in the country over 20 years, which had been one of the poorest countries in the world. Fidel's confidence in the development of Chinese socialism would also be reflected in his second visit in 2003. I must say that Fidel was key in the design of Cuba's relations with China and its vision for the future, allowing cooperation to be established on strategic issues, including medical services, biotechnology, tourism, educational exchange, among other topics.

The exchanges of high-level visits and the consolidation of strategic political dialog have been fundamental foundations of relations over the 60 years. Regular exchange has taken place between the leaders of the two parties, with the previous Army General, First Secretary of the Communist Party of Cuba, visiting China three times-1997, 2005 and 2012-while President Miguel Díaz-Canel Bermúdez first visited China in 2013, then as Vice President, and in 2018 as President. Visits to Cuba were made by Presidents Jiang Zemin, in 1993 and 2001, by Hu Jintao, in 2004 and 2008 and Xi Jinping in 2011, then as Vice President and in 2014 as President, as well as other top Chinese leaders.

The union between the revolutions of Cuba and China was something perfectly logical in the historical development of the life of both countries, because they were two revolutions that understand each other in many areas, including the economiccommercial sphere, people-to-people exchanges, the ideological, the cultural, the educational, foreign policy, cooperation in science, technology, and the environment.

China continues to establish itself as our second-largest commercial partner, a fundamental source of financing under favorable conditions and the main technological supplier for the systematic execution of prioritized projects for the economic and social development of our country. Cuba, for its part, is also consolidating itself as a stable supplier of sugar, nickel, lobster, rum, and tobacco for the Chinese market and in an incipient way of highly effective and innovative biotechnological products.

Many Chinese companies are involved in priority projects in Cuba, and many of these linked to the construction and modernization of infrastructure, telecommunications, renewable energies, the tourism sector, and so on, in every important sphere in the life of the country.

Cuba values the extension of the Belt and Road Initiative to our region, its new dimensions, the strengthening of the China-CELAC Cooperation Forum, which was born from the agreements adopted at the Second CELAC Summit held in Havana. These are all spaces that represent unique opportunities for our countries for the development of infrastructure, the improvement of regional connectivity, and the construction of control and prevention mechanisms in the field of health. 
The COVID-19 pandemic has not only brought our countries closer together with the common objective of bringing welfare and health to our people, but also expanded trade ties that have led to gratifying results. Bilateral cooperation in the biotechnology sector has reached unprecedented levels, which we are determined to continue expanding, for the benefit of both people.

\section{Cooperation between Cuba and China in Biotechnology and Pharmaceuticals}

The bilateral relationship in the biotechnology and pharmaceutical sector between the People's Republic of China and Cuba has seen steady development over the past 16 years with remarkable results.

On November 22, 2004, the governments of both countries, recognizing the progress of collaboration in this area, signed a Memorandum of Understanding (MOU) in the presence of the historic leader Commander in Chief Fidel Castro and the Honorable Mr. Hu Jintao, then-President of The People's Republic of China. This Memorandum was renewed in 2009 and extended during the successful visit to Cuba by President of China, Mr. Xi Jinping in July 2014, as well as in the Proceedings of the seventh, eighth, ninth, and tenth meetings of the Joint Group for Biotechnological Cooperation Cuba-China.

This MOU established the general framework of cooperation in the biopharmaceutical sector, allowing both countries to advance and consolidate their relationship.

BioCubaFarma promotes cooperation and business with Chinese companies and institutions in the field of biotechnology and pharma industry in China under different cooperation models. The relationship is formed to advance product development and ultimately gain faster registration approvals for the products in China. Cooperation in the biotechnology sector shows outstanding results today. Three Chinese/Cuban joint ventures with important contributions to human health and agriculture have been established: (1) Biotech Pharmaceutical Co., Ltd in Beijing, (2) Changchun Heber Biological Technology Co., Ltd in Jilin province, and (3) Shandong Lukang Heber Co., Ltd in Shandong province.

The Centers of Cuban Biotechnology have been incorporated into these companies, all established in the People's Republic of China, innovative products for the treatment of diseases of high incidence like cancer and hepatitis, among others, transferring a total of ten technologies to China thus far.

So far, BioCubaFarma has four products registered in China: (1) Nimotuzumab: a humanized monoclonal antibody for the treatment of nasopharyngeal cancer and other types of tumors from Biotech Pharmaceutical that has led to the treatment of more than 50,000 Chinese patients and is now seeking approval for two other tumor indications (head and neck and esophagus); (2) human recombinant interferon alpha $2 \mathrm{~b}$ for the treatment of Hepatitis B and C from Changchun Heber Biological 
Technology; (3) Ateromixol (PPG) for hypercholesterolemia from Hubei ChinaCuba Biopharmaceutical Co., Ltd; and (4) Aikexian, a biofertilizer from JV Shandong Lukang Heber Biotechnology Co., Ltd.

There is also a Cuba-China industrial complex for the production of PPG and other natural products in the New East Lake High-tech Zone in Wuhan. Likewise, in Cuba, plants manufacturing soft capsules for important natural products, with the assistance and support of Hubei China-Cuba Biopharmaceutical Co., Ltd, and a plant producing biosensors with technology from Changsha Sinocare Inc., have been constructed.

BioCubaFarma is also working with local Chinese governments in Chengdu, Yongzhou, Shanghai, and Changchun, as well as universities and institutes (University of Science and Technology of Shanghai, Institute of Materia Medica of Shanghai, Institute of Neurosciences of Shanghai, and University of Science and Electronic Technology of Chengdu) to foster innovation in the biotech field by setting up R\&D centers and joint laboratories to introduce and jointly develop Cuban proprietary technologies for the Chinese market. Of particular interest are the China-Cuba Biotechnology Joint Innovation Center, a research base jointly established by the Yongzhou Municipal Government and BioCubaFarma in the Yongzhou Economic and Technological Development Zone, and the Collaboratory for Neuroscience and the Brain Mapping Project Development between the University of Science and Electronic Technology (UESTC) from the Tianfu New Area, Chengdu, and the Cuban National Center for Neurosciences (CNEURO), all of the upmost priority for bilateral cooperation in the sector.

Cooperation between Cuba and China in the biopharmaceutical sector has reached a new stage, where new challenges should be addressed. These challenges include maintaining and increasing the sales of biotech products already sold in China and registering of BioCubaFarma's products currently produced in China for new indications. In addition, clinical studies for products positioned in the medium term should be accelerated to get into the Chinese market, such as the new indications of Nimotuzumab for cancer treatment, Heberprot-P for the treatment of diabetic foot ulcers, the therapeutic vaccine CIMAVAX against lung cancer, therapeutic vaccines for the treatment of Hepatitis B (HeberNasvac), and Heberkinasa (Proctokinasa) for the treatment of acute hemorrhoids.

BioCubaFarma in confident to continue growing the cooperation for development of joint projects in light of the possibilities offered by Cuba for foreign investment with the updating of its economic model.

\section{Cuban-Chinese Cooperation in Science, Technology, and the Environment}

Cuba and China have a long-standing cooperative relationship in areas of common interest. The Agreement of the Scientific and Technical Cooperation between the 
Governments of the Republic of Cuba and the People's Republic of China, signed in Beijing in 1989, laid the foundation for the establishment of a Joint Commission for Scientific and Technical Cooperation in order to assess and coordinate the compliance with cooperation programs.

To date, there have been eleven meetings of the Joint Committee on Intergovernmental Cooperation in Science and Technology in China and Cuba, respectively. The last one took place in 2019, and was chaired by Deputy Ministers from CITMA and MOST correspondingly. It was an opportunity for both sides to review achievements in biomedicine, brain science, and other fields of cooperation. As a relevant outcome of the meeting was signed, with final minutes included the main areas on future cooperation to boost and conduct in-depth exchanges on topics such as science park cooperation, personnel exchanges, and support for joint research.

Both sides agreed to promote practical cooperation in such fields as Biotechnology, Biomedicine and Neurosciences; Nanotechnology and Nanosciences; Climate Change, Natural Resources and Environment; Scientific and Technological Parks; Agricultural Science and Technology; and Young Talent Program, among others.

In the first quarter of 2020, the Cuba-China Joint Call for the development of Research Projects in Life Sciences, Nanotechnology and Nanosciences, and Agricultural Science and Technology (including Hybrid Rice) within institutions, scientific centers and enterprises from both nations was launched.

In the field of neurosciences, the Brain Mapping Project being carried out by Cuba, China and Canada stands out, which, due to its groundbreaking results, has been extended for three more years. Among other goals, the project "Precision Brain Health" aims to research early detection and management of pathological brain aging and identify the most effective treatments. In this effort, a successful triangular collaboration has been achieved among centers, universities, and institutions from the three countries.

Another significant accomplishment to highlight is the project of the Joint CubaChina Laboratory for Frontier Research in Translational Neuroethology at the University of Science and Electronic Technology of China (UESTC) in Chengdu, where research is carried out on the early detection, intervention, and rehabilitation of multiple neurodegenerative diseases and mental disorders. Additionally, China and Cuba's jointly owned technological products and services are reviewed and developed, which contribute to the promotion and the transformation of the high-tech industries in the two countries.

Cooperation between Cuba and China in other fields has also produced concrete results, such as in the environment with the donation of Chinese technology and equipment for evaluating the air quality in Havana, as well as those for assessing earthquake data and the most damaged locations across the island. At the same time, it is quite relevant to underline the granting of scholarships to talented young Cuban scientists for their training in innovative environmental technologies.

China has been successful in the development of scientific and technological parks, as well as high technology zones. In this spirit, we are seeking the introduction of Chinese companies in the scientific parks of Cuba, as well as the development 
of business by Cuban high-tech companies and their Chinese counterparts for the production and commercialization of innovative products.

The first Cuban science and technological park was opened in 2019, known as Havana Scientific-Technological Compound, and is located at the University for the Information Sciences (UCI). The name $3 \mathrm{CE}$ is an acronym related to the link between creation, growth, competitiveness, and companies. The country looks forward to extending this experience to other centers of higher education in different regions of the island. Havana Park is included in the Portfolio of Opportunities for Foreign Investment 2020-2021.

There is another Cuban sci-tech park at Matanzas, which has the unique model of being a trading company made up of five shareholders that have already signed their first export contract (a computerization project worth USD 200,000). Similar to Havana Park, the main specialty is the Information and Communications Technology (ICT), but it is looking to expand into other areas of knowledge taking advantage of the location at the campus of the university.

Such cooperation is also meant to share and enrich our experiences and knowledge in facing common challenges related to the economic, geographical, and cultural particularities of developing countries.

\section{Cuba and China-Paradigmatic Relations in the Fight Against COVID-19}

The new SARS-CoV-2 coronavirus, responsible for the current pneumonia outbreak named COVID-19, has been the main challenge to global development in 2020, creating an environment full of uncertainty and suffering for the international community. The devastating COVID-19 pandemic has demonstrated the significant need to overcome political and ideological differences and seek common solutions to global challenges through cooperation and solidarity.

In the context of these exceptional circumstances in which humanity has had to face a totally unknown, unexpected, and devastating disease, Cuba and China, two socialist nations, have shown a high degree of political generosity and commitment by confronting the pandemic with solidarity, discipline, and sacrifice. Based in strong political willingness, both countries have succeeded in strengthening mutual cooperation and strategic communication, thus ratifying an essential principle of bilateral relations in terms of mutual support during the most difficult times.

Against the backdrop of the celebration of the sixtieth anniversary of bilateral relations in 2020, the joint fight against COVID-19 has been the best symbol of the unique nature of Sino-Cuban relations. Comrade Raúl Castro Ruz, First Secretary of the Central Committee of the Communist Party of Cuba, and Comrade Miguel DíazCanel Bermudez, President of the Republic of Cuba, sent messages of solidarity to Comrade Xi Jinping, Secretary General of the Central Committee of the Communist Party of China and President of the People's Republic of China in January when China 
became the first country affected by COVID-19. Soon after, the presidents of both countries held a telephone conversation to re-affirm their solidarity and willingness to strengthen mutual support in the context of the health crisis.

Under the firm leadership of their respective Communist Parties, and in accordance with their specific realities, Cuba and China have launched, respectively, decisive battles to prevent and control the spread of COVID-19, with the priority and undeniable premise of safeguarding the lives of their people. The idea that people's lives come first and are above economic prejudices has been a common and fundamental policy of both countries and is very different from what was done in other nations with different political systems.

In the context of the global fight against COVID-19, Cuba and China have cooperated, making the highest priority saving human life. I would like to take this opportunity to reiterate once again my deep gratitude to the Chinese Party, Government, and business community, for their valuable help in confronting the pandemic, which has allowed Cuba to receive important supplies, medicines, and medical equipment, despite the strong obstacles imposed by US government's blockade policy against Cuba and its extraterritorial impact, whose effects have been accentuated during last year.

For Cuba, the effectiveness of the fight against COVID-19 is mainly due to our solid health system and the strengths of our scientific potential. For instance, the application of 22 innovative Cuban biotechnology products in different clinical research protocols is to prevent infection in a high-risk populations and to treat and control severe and critical patients with COVID-19.

The human recombinant interferon alpha $2 \mathrm{~b}$, manufactured by the Sino-Cuban company Changchun Heber Biological Technology Co., Ltd. with Cuban technology, at the request of China's National Health Commission, was successfully used to fight the virus in 11 Chinese provinces, another good example of cooperation between Cuba and China to tackle the COVID-19 outbreak. Cuban interferon alpha 2b has also been requested by other countries to curb SARS-CoV-2 amid the pandemic.

Other innovative products from BioCubaFarma, which have been successfully used in the Cuban outbreak, can also be offered to China and other countries to fight COVID-19. Among them, Biomoduline T (a natural biological drug as immunomodulatory of the immune system) was used in 8,000 elderly people with a reduction of more than $40 \%$ in acute respiratory infections and a decrease in hospital admissions and mortality; Heberferon (combination of recombinant human interferon alpha $2 b$ with recombinant human gamma interferon in a single vial) is a potent antiviral drug for the treatment of SARS-CoV-2 positive patients with certain comorbidities. On the fourth and seventh days after using Heberferon, $37 \%$ and $78 \%$ of patients were free of the virus according to PCR tests.

The survival rate in critical patients using Jusvinza (a HSP60-derived immunoregulatory peptide for the treatment of cytokine storms on patients positive to SARSCoV-2) was $73.7 \%$, while in severe patients it was $91.3 \%$, with an overall survival rate of $86 \%$. The product was approved by the Cuban regulatory entity CECMED for extensive compassionate use in severe COVID-19 patients with hyper-inflammation. Itolizumab (an anti-CD6 humanized monoclonal antibody) reduces circulating levels 
of IL-6 in severe and critical patients positive for SARS-CoV-2. The rate of improvement of respiratory distress in critical patients using Itolizumab was 70\%, while in severe patients, it was $90 \%$, with an overall survival rate of $80 \%$.

Cuba has achieved all this despite the fact that the US government has drastically escalated the blockade against the small island, taking advantage of the terrible circumstances of COVID-19. The blockade has always been criminal, an act of genocide and economic warfare against the Cuban people, but the cruelty of its application during a pandemic is unprecedented.

Finally, I should mention the work of Cuban and Chinese doctors and all supportive health workers. Health personnel have worked as true heroes. They have been essential to saving people's lives in the face of this pandemic and have been bridges of solidarity to different latitudes beyond national borders. China, for its part, has provided assistance to more than 150 countries, regions, and international organizations during the pandemic. Cuba, despite its limited resources, has sent more than 40 medical teams to more than 30 countries to fight COVID-19. At the same time, some Cuban and Chinese medical teams have maintained coordination in third countries and contributed jointly to the fight against COVID-19. Even in the context of this act of solidarity with Cuba's international medical cooperation, the USA has sought to discredit and undermine, with an immoral position in circumstances where the world needs more cooperation and joint efforts to overcome this pandemic.

Cuba and China have great potential to strengthen public health cooperation, promoting health services and the production and trade of medicines, and other health supplies. Both countries have offered mutual solidarity and support, turning the joint fight against COVID-19 into a new symbol of friendship and an example of both bilateral and global cooperation. This kind of paradigmatic relationship is what humanity requires to successfully defeat this pandemic.

The high-level bilateral political relationship and the unwavering friendship between the two communist parties, governments and people, allow us to continue to strengthen a strategic alliance and a special relationship. As socialist countries that are, in addition to good friends, brothers and comrades, Cuba and China have unlimited potential, which both sides must take advantage of for the benefit of our people and humanity. 


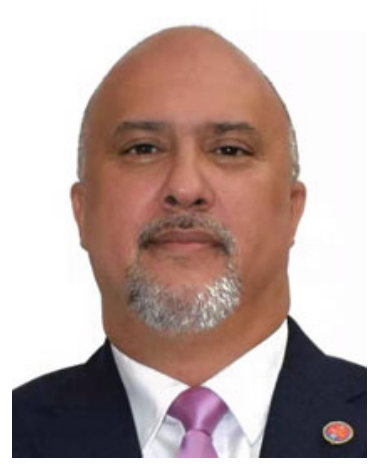

H.E. Mr. Carlos Miguel Pereira Hernández is the ambassador of the Republic of Cuba to the People's Republic of China. He has been the ambassador of Cuba to China since 2019. Mr. Hernández graduated from the Higher Institute of International Relations Raúl Roa García where he received a degree in international political relations. He also studied at Beijing Language and Culture University and Peking University. Mr. Hernández joined the official Asia and Oceania Bureau, Ministry of Foreign Affairs in 1990. He served as Third Secretary, Second Secretary, and First Secretary in the Embassy of Cuba in China and he was also the ambassador to the People's Republic of China from 2006 to 2011.

Open Access This chapter is licensed under the terms of the Creative Commons AttributionNonCommercial-NoDerivatives 4.0 International License (http://creativecommons.org/licenses/bync-nd/4.0/), which permits any noncommercial use, sharing, distribution and reproduction in any medium or format, as long as you give appropriate credit to the original author(s) and the source, provide a link to the Creative Commons license and indicate if you modified the licensed material. You do not have permission under this license to share adapted material derived from this chapter or parts of it.

The images or other third party material in this chapter are included in the chapter's Creative Commons license, unless indicated otherwise in a credit line to the material. If material is not included in the chapter's Creative Commons license and your intended use is not permitted by statutory regulation or exceeds the permitted use, you will need to obtain permission directly from the copyright holder.

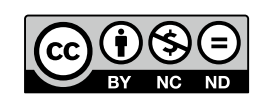

